\title{
МЕТОДЫ АТОМНО-СПЕКТРАЛЬНОГО АНАЛИЗА
}

Захаров Ю.А.

Казанский (Приволжский) федеральный университет, Казань, Россия

zaha1964@yandex.ru

DOI: 10.26902/ASFE-11_04

Методы атомно-спектрального анализа опираются на природное свойство каждого химического элемента менять свое состояние дискретно, в соответствии с индивидуальными значениями энергии. При внешнем воздействии атомы возбуждаются, поглощая порции энергии, и быстро возвращаются в основное состояние, испуская кванты, количество которых, как правило, пропорционально числу этих атомов. Данное уникальное явление позволяет по спектрам поглощаемой и испускаемой энергии регистрировать присутствие химических элементов в пробе того или иного вещества, распознавать их и определять количество. Делать это можно разными способами возбуждения и регистрации спектров. Поэтому атомно-спектральный анализ в настоящее время представлен рядом методов: атомно-эмиссионным, атомно-абсорбционным и атомно-флуоресцентным. Они отличаются аналитическими характеристиками, имея специфические особенности, недостатки и преимущества, но, как правило, дополняют друг друга и остальные методы химического анализа при исследовании твердых, жидких и газообразных веществ на макро, микро- и следовые элементы.

В докладе рассмотрена современная иерархия методов атомно-спектрального анализа при решении рутинных и нестандартных аналитических задач в зависимости от вида проб, необходимых чувствительности, точности и производительности. Дается обзор последних моделей спектрометров - серийных и опытно-экспериментальных. Обсуждаются тенденции развития этой области аналитической техники и изобретательская активность на основе соответствующего патентного исследования.

В случае атомно-эмиссионного метода прогресс достигнут в конструкции и параметрах дуговых и ИСП источников, плазмотронов, дозаторов проб-порошков и конечно же твердотельных многопиксельных фотоприемников, позволяющих работать в режимах накопления фотонов, а также сцинтилляций.

Атомно-абсорбционный метод активно развивается, благодаря внедрению универсального для всех определяемых элементов просвечивающего источника стабилизированной дуговой ксеноновой лампы, а также спектрометров высокого разрешения с многопиксельными фотоприемниками. Стыковка их с графитовой печью, работающей в режиме двухстадийной зондовой атомизации открывает реальную перспективу для прямого одновременного анализа твердых и других проб сложного матричного состава на многие элементы. Усовершенствования систем подачи проб, их атомизации и фотометрирования атомного пара наблюдаются и в методе атомной флуоресценции.

Несмотря на долгую историю применения в аналитической химии обсуждаемых в докладе методов, их потенциал до конца не раскрыт. И это обстоятельство питает живой интерес к ним со стороны многочисленных пользователей и разработчиков аппаратуры и методик. 